Antonio E. Nardi ${ }^{1}$

OChttps://orcid.org/0000-0002-2152-4669

Jorge Adelino R. da Silva² Ohttps://oridi.org/000-0003-2395-0175

Mauro V. Mendlowicz ${ }^{3}$ (- http://orcid.org/0000-0002-8891-0548

José C. Appolinário ${ }^{4}$

ohttps://orcid.org/0000-0002-6089-4400

\section{Professor Eustachio Portella Nunes Filho (1929-2020): a great mentor of culture and humanistic philosophy and an enduring source of inspiration for generations of psychiatrists and psychoanalysts}

D0I: 10.1590/0047-2085000000293

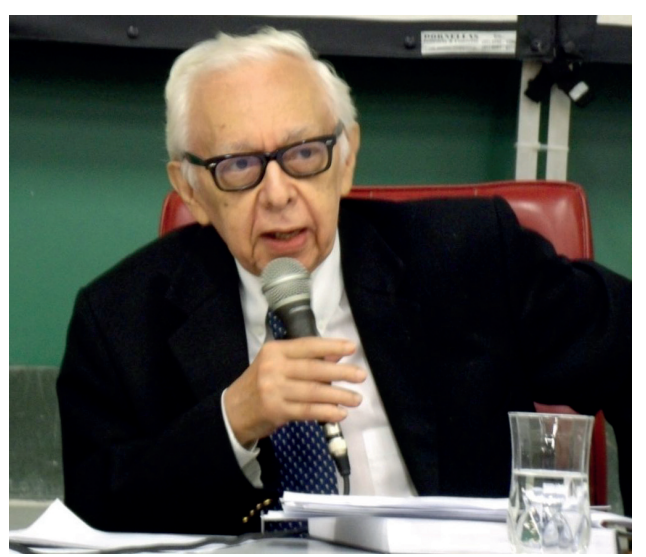

Figure 1. Professor Eustáchio Portella Nunes Filho in one of his inspiring lectures at the Institute of Psychiatry, Federal University of Rio de Janeiro, Brazil.
Brazilian psychiatry and psychoanalysis, in general, and the Institute of Psychiatry of the Universidade Federal do Rio de Janeiro, in particular, are in mourning with the passing of the noted psychiatrist, psychoanalyst, lecturer, writer and, above all, the great humanist, professor Eustáchio Portella Nunes Filho. Professor Portella was - and is an example to be followed by everyone who studies and works in the fields of psychiatry and psychoanalysis. He was one of the most outstanding professors of our times, a truly encyclopedic scholar, a renowned intellectual and a compassionate physician who knew well the troubled depths of the human soul in pain. His magnetic personality and sharp intellect drew people to him. Not a few medical students experienced a change of mind after attending one of his inspiring classes and decided to become psychiatrists themselves (Figure 1).

Professor Portella was born on June 10, 1929, in Valença, in the state of Piauí (PI). His parents were Eustáchio Portella Nunes, twice the mayor of the town, and Maria de Deus Nunes. In 1936, the family moved to the state capital Teresina where he and his brothers could get a better education. The young Eustáchio Portella loved the books. One of his dearest early memories was the loving scent of the paper (much like Proust's remembrance of the smell of the "petites madeleines") of the newly printed books that arrived to his home by mail. The childhood and adolescence memories from Valença and Teresina were indelibly imprinted on Professor Portella's own being and he would often say that his roots have always been there.

In 1948, Eustáchio Portella Nunes Filho moved to the city of Rio de Janeiro, then the federal capital, to study Medicine at the University of Brazil (the first, historical name of the Universidade Federal do Rio de Janeiro) and graduated five years later. Still as a last year medical student, he taught his fellow students psychopathology and clinical psychiatry, the first step in an illustrious academic career.

In 1954, Eustáchio Portella Nunes Filho was hired as clinical instructor at the Institute of Psychiatry of the University of Brazil (IPUB) thus officially beginning his teaching career. In the same year, he did a fellowship in Child Neuropsychiatry at the University of Lisbon. In 1963, Professor Portella completed his habilitation as a Privatdocent. Between 1957 and 1965, Professor Portella was trained as a psychoanalyst in the Psychoanalytic Society of Rio de Janeiro

Received in: 0ct/11/2020. Approved in: Nov/11/2020

1 Institute of Psychiatry, School of Medicine, Federal University of Rio de Janeiro; National Academy of Medicine and Brazilian Academy of Sciences, Rio de Janeiro, RJ, Brazil.

2 Professor of Institute of Psychiatry, School of Medicine, Federal University of Rio de Janeiro; Director of the Institute of Psychiatry, Federal University of Rio de Janeiro, Rio de Janeiro, RJ, Brazil.

3 Department of Psychiatry and Mental Health, Federal Fluminense University, Niterói, RJ, Brazil.

4 Institute of Psychiatry, Federal University of Rio de Janeiro, Rio de Janeiro, RJ, Brazil.

Address for correspondence: Antonio E. Nardi. Email: antonioenardi@gmail.com 
(SPRJ). In 1970, he completed his training in Psychiatry through the Brazilian Psychiatric Association (ABP). Professor Portella was the full professor of Medical Psychology in Universidade Gama Filho between 1964 and 1968. In the State University of Rio de Janeiro, Professor Portella was the head of the psychiatric services of the Hospital Universitário Pedro Ernesto and the substitute professor of Psychiatry, Psychology, and Psychopathology from 1971 to 1974 . He lectured Clinical Psychiatry and Therapeutics for master and doctoral degree candidates at the Universidade Federal do Rio de Janeiro and was appointed medical director of the IPUB in 1974. Professor Portella also played a major role in the development of the post-graduation programs in psychiatry in Brazil. He supervised dissertations and theses of young psychiatrists 1,2 many of whom would later become scientific leaders in their areas of expertise.

In 1976, professor Portella became the full professor of Clinical Psychiatry and Mental Health of the Universidade Federal do Rio de Janeiro. His thesis, "Obsession and Delusion: Neurosis and Psychosis" was an instant classic in psychiatry and psychoanalysis (Figure 2). In 1985, Professor Portella became a member of the National Academy of Medicine and in 1988, the president of the Latin American Psychoanalytic Federation.

From the very beginning of his career, Professor Portella showed an eclectic interest in different aspects of psychiatry, ranging from psychopathology to the biological and psychological treatments for mental illness ${ }^{3-7}$. A prolific author, he published several papers in the Jornal Brasileiro de Psiquiatria covering a wide range of subjects. In the field of psychopathology, one could highlight two particularly important theoretical papers, discussing in deep the phenomenology of consciousness ${ }^{3}$ and the nature of angst in the perspective of several authors ${ }^{4}$. As a researcher, Professor Portella critically analyzed empirical papers reporting the effectiveness of different biological interventions available at the time $e^{5,6}$. He also sought to adapt psychoanalytic techniques to the treatment of patients with severe mental disorders ${ }^{7}$. Professor Portella published several important books during his academic career, such as the above mentioned "Obsessions and Delusions: Neurosis and Psychosis"8 (Figure 2) and "Freud and Shakespeare".

In his writings and lectures, Professor Portella was keen to highlight the enormous influence of psychoanalysis not only on philosophy and psychiatry, but also upon the contemporary mindset as a whole. The intellectuals, the media, the working class, all regularly employ psychoanalytic terms, such repression, complex, and sublimation, in their daily lives although many of them have not read even a single page written by Sigmund Freud.

Always a literary man, Professor Portella was deeply influenced by the great writers of the past. He read and reread

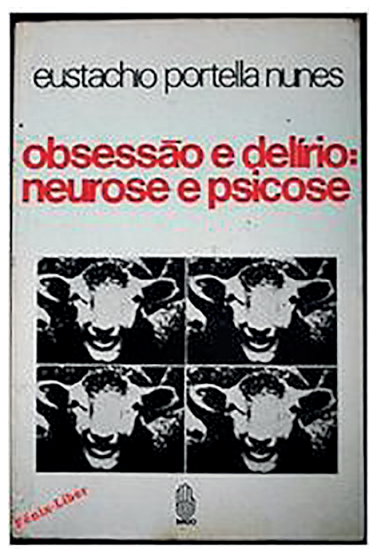

Figure 2. One of the famous books of Professor Eustáchio Portella Nunes Filho. "Obsession and Delusion: Neurosis and Psychosis" (Imago, Rio de Janeiro, 1976).

many times the Greek tragedies, Shakespeare, Goethe, and other classical works and often quoted them in his lectures. His favorite quote was from Hamlet Act 2 Scene 2 Page 21 "If you pay everyone what they deserve, would anyone ever escape a whipping? Treat them with honor and dignity. The less they deserve, the more your generosity is worth". The lessons of the masters of the past helped Professor Portella perfect the skills needed to delve into the inner realities of the patients and to provide them with the much needed solace.

"If I have seen further it is by standing on the shoulders of Giants", Isaac Newton wrote to Robert Hook in a letter dated form February 6th, 1676. Our generation was indeed lucky to have a broad-shouldered giant as Professor Eustachio Portella Nunes Filho as a leader, as a master and as a friend.

\section{REFERENCES}

1. Versiani M. Personalidade Psicopática [tese de doutorado]. Rio de Janeiro: Programa de Pós-Graduação em Psiquiatria e Saúde Mental (PROPSAM), Instituto de Psiquiatria, Universidade Federal do Rio de Janeiro; 1980.

2. Appolinario JC. Menopausa: Avaliação dos sintomas de humor em mulheres com síndrome do climatério que procuram atendimento médico [tese de doutorado]. Programa de PósGraduação em Psiquiatria e Saúde Mental (PROPSAM), Instituto de Psiquiatria, Universidade Federal do Rio de Janeiro; 1997.

3. Nunes EP. Fenomenologia da Consciência. J Bras Psiquiatr. 1961;10(4):379-87.

4. Nunes EP. Angústia e Psicopatologia. J Bras Psiquiatr 1954;(4):363-81.

5. Silva LM, Costa DG, Nunes EP. Lobotomia em pacientes esquizofrênicos. J Bras Psiquiatr. 1954;3(1):3-13.

6. Silva LMS, Zusman W, Nunes EP. Técnicas de Sono Prolongado em Psiquiatria. J Bras Psiquiatr. 1954;(2):166-82.

7. Nunes EP, Schneider G. Psicoterapia de Grupo em Psicóticos. J Bras Psiquiatr. 1964;13: $317-29$.

8. Nunes EP. Obsessões e Delírio: Neurose e Psicose. Rio de Janeiro: Imago; 1976.

9. Nunes EP. Freud e Shakespeare. Rio de Janeiro: Imago; 1989. 